\title{
FAT EMBOLISM: AN AID TO DIAGNOSIS
}

\author{
Alan R. Gurd, Belfast, Northern Ireland
}

Since Zenker described the first case of fat embolism in 1862 there has never been a reliable diagnostic test for this condition. There can be no doubt that one is required: the clinical picture is very variable and often missed, and all too often the diagnosis is made post-mortem.

Fat normally exists in the blood as glycerides, cholesterol, esters, phospholipids and free fatty acids. The glycerides are composed mainly of triglycerides (Derian 1965). This fat exists either in solution, attached to beta-lipoproteins, or as a minute suspension of particles (chylomicrons), less than 1 micron in diameter, which consist of about 97 per cent triglyceride (Swank and Wilmot 1951).

Many attempts have been made to detect changes in either the quantity or the quality of the circulating fat or in the serum enzymes concerned with lipid metabolism.

\section{DIAGNOSTIC PROCEDURES}

Serum lipase-The enzyme lipase is responsible for hydrolysis of neutral fats with the resultant production of glycerol and free fatty acids. Struppler (1940) noted an elevation of this enzyme in patients with fractures. Peltier and Lai (1958) suggested that detection of a rise in serum lipase might be of value in diagnosing fat embolism; however they found that although this did occur it was not specific and that the diagnosis remained presumptive.

TABLE I

Clinical features of Fat Embolism

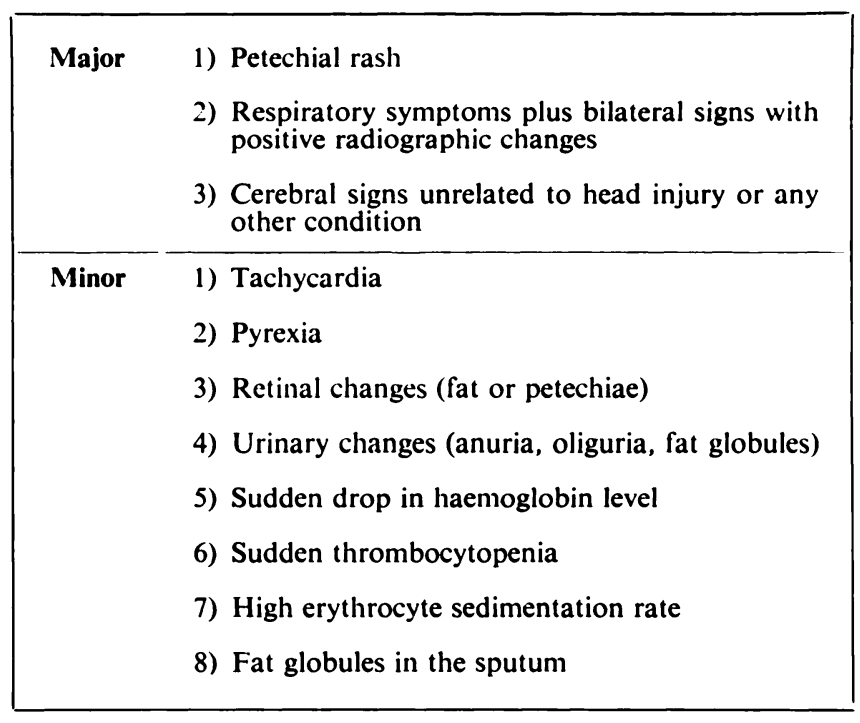

Serum triglycerides-A rise in serum triglycerides is often accepted as diagnostic of fat embolism (Johnson and Svanborg 1956; O'Driscoll and Powell 1967).

An attempt was made to confirm the usefulness of this estimation. Triglyceride estimations were carried out in two groups of patients. Thirty were selected randomly as controls, none of these having had fat embolism or having been injured (Fig. 1). Thirty were patients with 
clinically diagnosed fat embolism (Fig. 2). The clinical diagnosis was made in any case of injury in which at least one major feature plus four minor features of fat embolism were present (Table I).

Results -The mean average of the triglycerides in the control group was $117 \cdot 3$ milligrams/100 millilitres, and in the fat embolism group 119.4 milligrams/100 millilitres. Statistically there is no significant difference between the two groups $(t=0.372 \therefore 0.8>p>0.7)$.

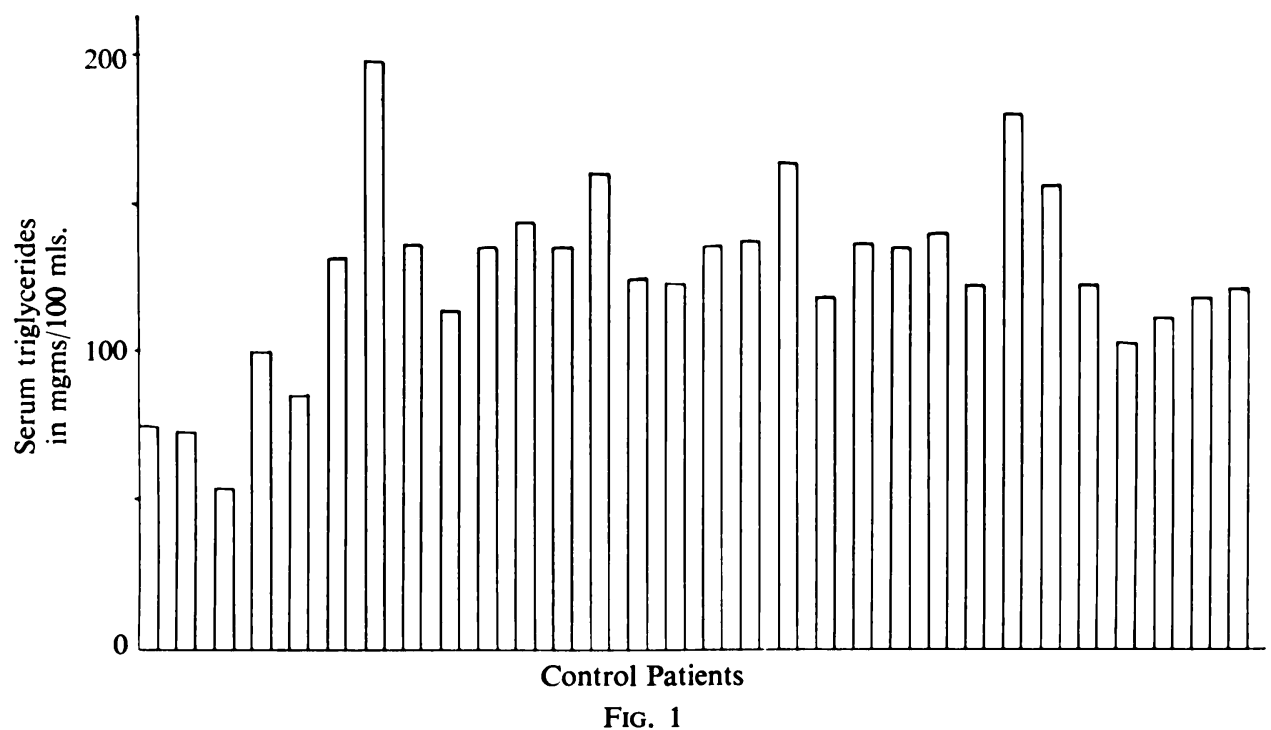

Serum triglyceride levels in thirty random patient samples.

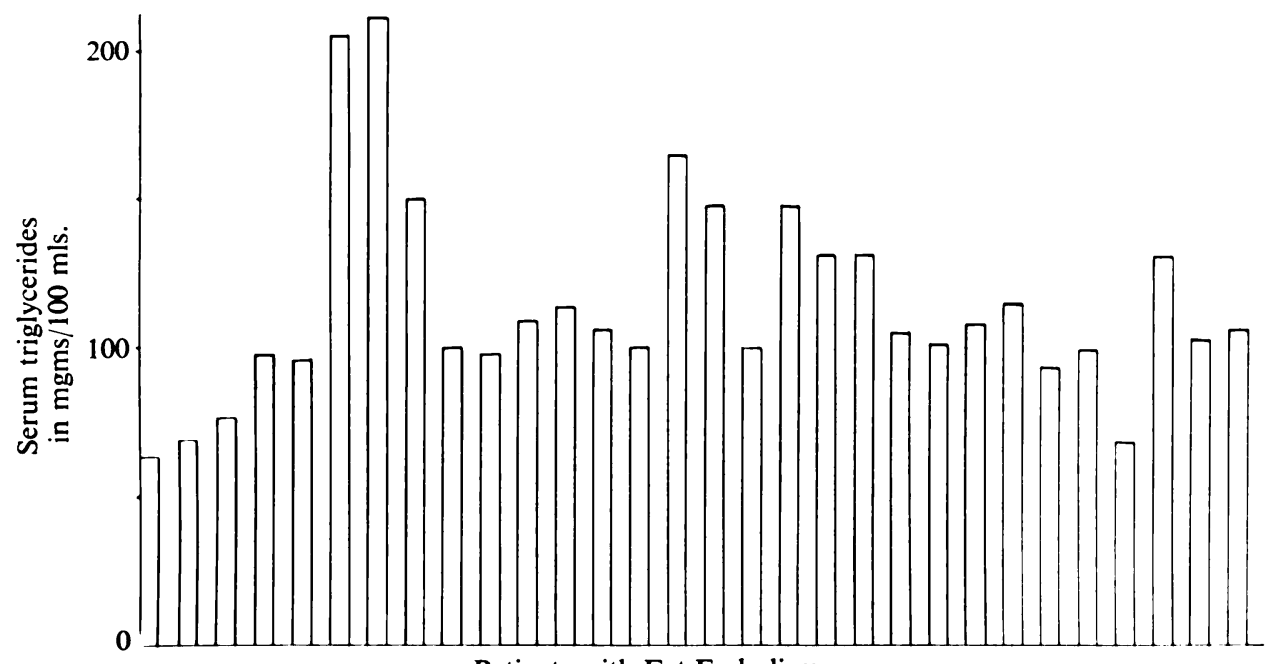

Patients with Fat Embolism

Fig. 2

Serum triglyceride levels in thirty cases of fat embolism.

This finding is in agreement with the observations by Scuderi (1941), Warren (1946) and Bergentz (1961) that a qualitative assessment of serum lipids is of no diagnostic value in fat embolism.

Fat globulinaemia-Robb-Smith (1941) postulated that the essential feature of fat embolism was fat in the circulating blood, not in the fine emulsion of a metabolic lipaemia, but in globules 
large enough to obstruct arterioles and capillaries. Harman and Ragaz (1950) have shown that fat globules smaller than 8 microns in diameter are effectively dealt with by the organism but that if larger they behave as emboli. Microscopy of the plasma for fat globules was first suggested by Scuderi (1941). A test was described by Peltier (1954) who reported a method based on staining plasma fat with a water-soluble fluorochrome dye, phosphine-3R. Using fluorescent microscopy he found fat globules of 7 to 14 microns in diameter. Sevitt (1962) criticised this technique because the stained drops of plasma were allowed to dry on slides before being examined; he thought that drying might disturb the equilibrium of the normal fat emulsion and permit chylomicron flocculation. The other major drawback to this method is that it affords only a qualitative assessment of the circulating fat (Kane, Peller, Rudolph and Fink 1961).

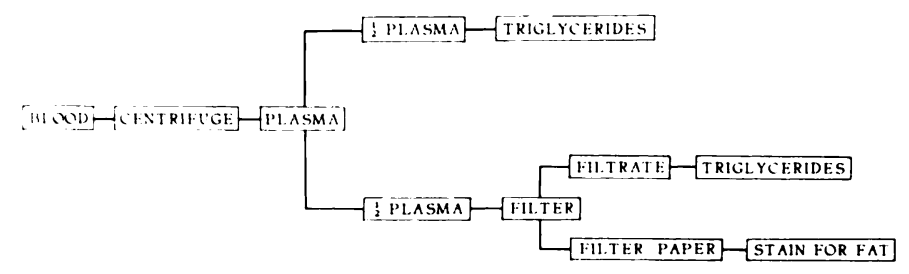

Fig. 3

Diagram showing the procedure for assessing pathological fat globules.

\section{NEW PROCEDURE}

A method has been devised which not only permits identification of pathological fat globules but also allows quantitative assessment.

Materials-The following are required: 1) millipore microfilters: S.C.W.P. 02500, pore size 8 microns, 2.5 centimetres in diameter. 2) Filter holder 2.5 centimetres in diameter. 3) Glass syringes, collecting tubes, pipettes and slides. 4) Laboratory centrifuge. 5) Routine laboratory microscope with a good light source.

Method (Fig. 3)-A blood sample is taken, preferably of about 10 millilitres but as little as 2 millilitres will suffice, and allowed to clot. The specimen is centrifuged for ten minutes at 3,500 r.p.m. and all the supernatant serum is pipetted off into a glass tube. This specimen is

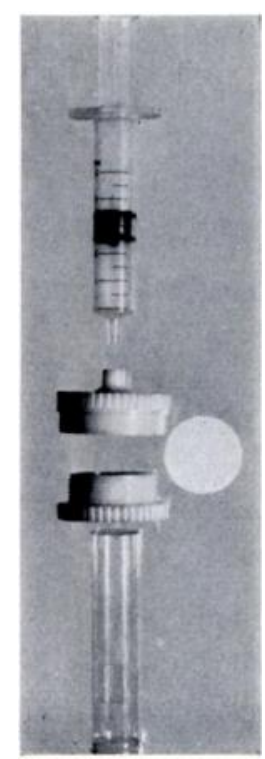

FIG. 4 mixed well and split into two roughly equal portions. The first portion is kept for estimation of the triglyceride content and the second is passed through a millipore microfilter with a pore size of 8 microns (Fig. 4). The filtrate is kept for triglyceride estimation and the filter paper is placed on a glass slide and stained for fat with alcoholic Sudan IV (Scharlach R). Triglycerides are estimated by a microtechnique described by Van Handel and Zilversmit (1957).

Precautions-All instruments used, including syringes, glass tubes, filter holder, pipettes and slides, are washed twice in alcohol-ether and then dried carefully. During filtration, the serum must be allowed to drip slowly through the filter paper. Pressure tends to disperse the fat globules into the substance of the filter, making interpretation of the stained slide very difficult. After staining, the filter paper must be studied immediately; if it dries it becomes opaque.

Fig. 4 Apparatus required for filtering serum, using a millipore microfilter with pore size of
8 microns.

THE JOURNAL OF BONE AND JOINT SURGERY 


\section{RESULTS}

This method allows both a qualitative and a quantitative assessment of circulating globules of fat.

Qualitative change-Figure 5 is a photomicrograph of the stained filter paper from a case of fat embolism. The filter paper and other background material stain purple and the fat globules are readily visible and stain red. The diameter of these globules varies from 8 to 40 microns.

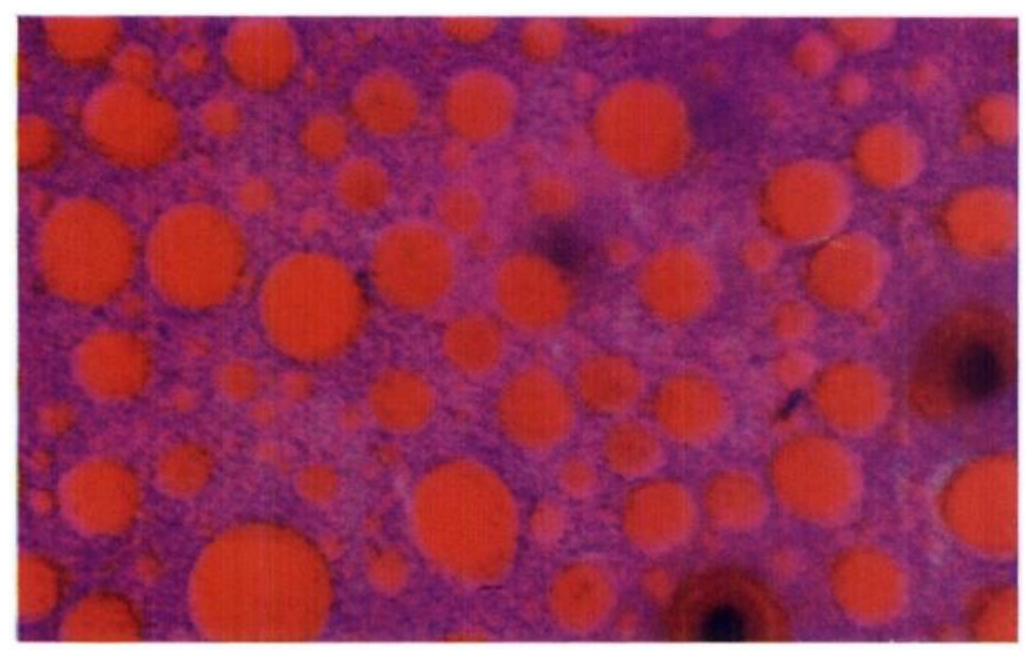

Fig. 5

Colour photomicrograph of filter paper stained for fat globules in a case of severe fat embolism. (Sudan IV, $\times 384$.)

Quantitative change-Triglyceride levels of the serum were measured before and after filtration, and the values are shown for the control group of patients in Figure 6, and for the cases of fat embolism in Figure 7. No difference was found in the two samples in the controls because in normal serum large fat globules do not appear in any significant amounts. A marked difference was evident in cases of fat embolism where the value after filtration was consistently less than that before filtration. In each case pathological fat globules were demonstrated on the filter paper. The mean average of triglycerides in cases of fat embolism before filtration was 119.4 milligrams $/ 100$ millilitres and after filtration $69 \cdot 2$ milligrams $/ 100$ millilitres (that is, $50 \cdot 2$ milligrams/100 millilitres on the filter as large fat globules). Statistically this feature is highly significant $(\mathrm{t}=6 \cdot 148 \therefore \mathrm{p}<0 \cdot 001)$.

\section{DISCUSSION}

It has been confirmed that the pathognomonic feature of fat embolism is the presence in the blood of fat globules larger than 8 microns in diameter, and not an increase in the amount of fat such as occurs in the metabolic lipaemia after ingesting a fatty meal. A method is described for identifying and assessing these globules and it has been demonstrated that the pathological fat extracted is composed mainly of triglyceride. This is in keeping with the findings of Hallgren, Kerstell, Rudenstam and Svanborg (1966) who showed that fat globules extracted from the lungs of patients with fat embolism were basically triglyceride.

This technique has been used to study all patients with major injury admitted to the Royal Victoria Hospital, Belfast, and the Belfast City Hospital. The results of 100 consecutive cases have been analysed; in thirty there was clinical evidence of fat embolism. Fat globules were sought on admission (an average of three and a half hours after injury), and then daily for seven days. Of the seventy patients not exhibiting clinical evidence of fat embolism, forty-seven did have circulating emboli immediately after injury, and ten still had some emboli 
circulating twenty-four hours later; but in none of these cases were globules found forty-eight hours or longer after injury. Thirty patients had clinical fat embolism and of these, twenty-one had a positive test for emboli immediately after injury. Twenty-four hours later fat globules were found in only five. The clinical features of fat embolism appeared at variable intervals after injury, the average length of the "latent period" being forty hours. In every case in which symptoms were evident circulating fat globules were found. It seems that fat globules are a frequent finding soon after injury but this feature is transient; however in those patients
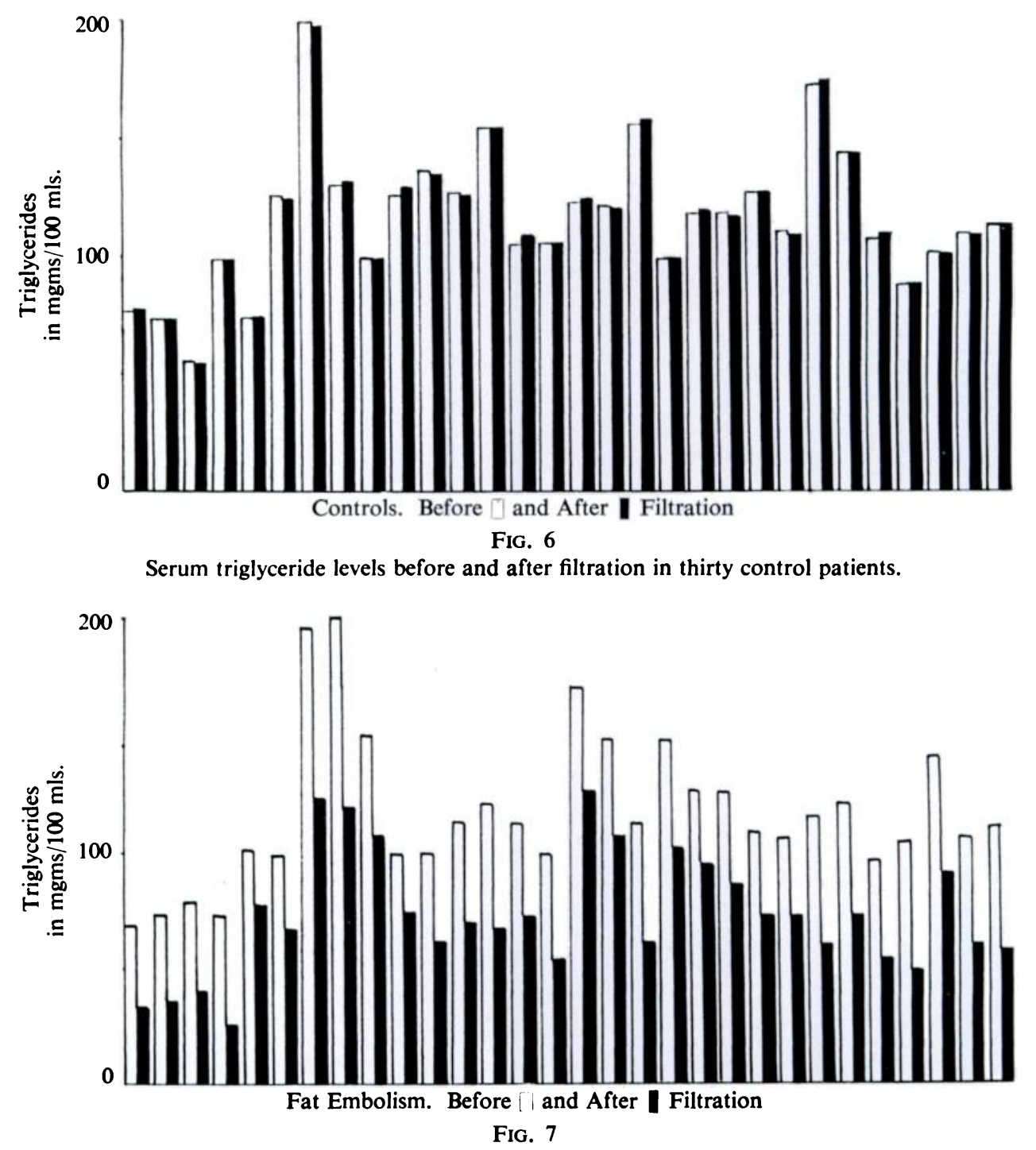

Serum triglyceride levels before and after filtration in thirty cases of fat embolism.

developing clinical fat embolism there seems to be a "second phase" of fat globules in the blood. It was also found that these emboli appear before the onset of clinical symptoms. The average "latent period" before fat globules appeared (excluding those cases in which they were found in the sample taken on admission) was thirty-five hours.

The amount of pathological fat was also significant. In patients without clinical features the average triglyceride before filtration was 112.5 milligrams/100 millilitres and after filtration 103.6 milligrams/100 millilitres (a difference of 8.9 milligrams/100 millilitres). In the thirty 
with clinical fat embolism the corresponding values were 119.4 milligrams/100 millilitres and $69 \cdot 2$ milligrams $/ 100$ millilitres (a difference of $50 \cdot 2$ milligrams $/ 100$ millilitres). Statistically the difference between these groups is significant. $\left(X^{2}=6 \cdot 13 \therefore 0.02>p>0.01\right)$.

The occurrence of fat globules immediately after injury does not appear to have much significance. Serial testing is necessary and it has been found useful in the early diagnosis of fat embolism or where the clinical features are doubtful. With experience it can be used to predict which patients are liable to develop a significant degree of clinical fat embolism. Its other great value is in conducting animal research where reliance on a clinical impression is obviously useless.

\section{SUMMARY}

1. A diagnostic procedure is described which is specific for fat embolism. It allows identification of the pathological fat globules on a stained slide.

2. The amount of pathological fat can be estimated by comparing the serum triglyceride levels before and after filtration.

3. The method is simple, reproducible and inexpensive.

I wish to thank those consultants of the Royal Victoria Hospital, Belfast, and the Belfast City Hospital for allowing me to study patients under their care. I also wish to acknowledge the help given me by $\mathrm{Mr}$ D. Neill and his Biochemistry Department, Mr R. Woods for the photographs and especially Mr R. I. Wilson for advice and encouragement.

\section{REFERENCES}

Brrgentz, S.-E. (1961): Studies on the Genesis of Posttraumatic Fat Embolism. Acta Chirurgica Scandinavica, Supplementum 282, p. 34

Derian, P. S. (1965): Fat Embolization-Current Status. Journal of Trauma, 5, 580.

Hallgren, B., Kerstell, J., Rudenstam, C.-M., and Svanborg, A. (1966): A Method for the Isolation and Chemical Analysis of Pulmonary Fat Emboli. Acta Chirurgica Scandinavica, 132, 613.

Harman, J. W., and Ragaz, F. J. (1950): The Pathogenesis of Experimental Fat Embolism. American Journal of Pathology, 26, 551.

Johnson, S. R., and Svanborg, A. (1956): Investigations with Regard to the Pathogenesis of So-called Fat Embolism. Annals of Surgery, 144, 145.

Kane, A. A., Peller, C., Rudolph, I., and Fink, H. (1961): Fat Embolism: Histochemical Studies with Fluorescent Light Source and Fluorochrome Dye. Annals of Surgery, 153, 465.

O’Driscoll, M., and Powell, F. J. (1967): Injury, Serum Lipids, Fat Embolism, and Clofibrate. British Medical Journal, 4, 149.

Peltier, L. F. (1954): Fat Embolism: The Detection of Fat Emboli in the Circulating Blood. Surgery, $36,198$.

Peltier, L. F., and LaI, S.-P. (1958): Fat Embolism: Changes in the Serum Lipase Levels of Patients after Fresh Fractures and Orthopedic Operations. Surgical Forum, 9, 748.

Robb-Smith, A. H. T. (1941): Pulmonary Fat-embolism. Lancet, 1, 135.

SCUDERI, C. S. (1941): Fat Embolism: A Clinical and Experimental Study. Surgery, Gynecology and Obstetrics, $72,732$.

SevitT, S. (1962): Fat Embolism, p. 200. London: Butterworths.

Struppler, V. (1940): Fettembolie; Untersuchungen und Beiträge zur Diagnostik. (Vorträge aus der praktischen Chirurgie, volume 26). Stuttgart: Enke.

Swank, R. L., and Wilmot, V. (1951): Chylomicra: Their Composition and Their Fate After Intravenous Injection of Small Amounts of Heparin. American Journal of Physiology, 167, 403.

Van Handel, E., and Zilversmit, D. B. (1957): Micromethod for the Direct Determination of Serum Triglycerides. Journal of Laboratory and Clinical Medicine, 50, 152.

Warren, S. (1946): Fat Embolism. American Journal of Pathology, 22, 69.

Zenker, F. A. (1862): Beiträge zur Normalen und Pathologischen Anatomie de Lungen, p. 31. Dresden: J. Braunsdorf.

VOL. 52 B, No. 4, NOVEMBER 1970 